www.jmscr.igmpublication.org

Impact Factor 5.244

Index Copernicus Value: 83.27

ISSN (e)-2347-176x ISSN (p) 2455-0450

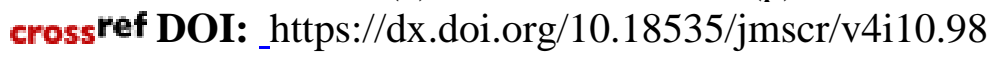

\title{
Raised PDW Common Hematological Parameters as a Prognostic \& Recovery Survival Index of Plasmodium Vivex Malaria for Acute Disease
}

\author{
Author \\ Dr Akshay Surana \\ Curewell Hospital Pvt. Ltd 19\1-C New Palasia Indore MP \\ Email: asurana06@yahoo.com 7741906945
}

\begin{abstract}
Aims \& Objectives: Improve the survival rate of patients. Reduced the morbidity and mortality of malaria due to plasmodium vivex Reduced the incidence of plasmodium vivex induced acute illness and prevent the complication.

Material \& Methods: Blood was collected in a sterile EDTA containing tube and processed following our established laboratory protocol .A complete blood counting including HB\%, PCV, Red cell indices, platelet count with platelets indices PDW and total white cell count and differential was done by Automated blood cell counter and peripheral blood smear examination by thin film and thick film. The all cell count indices including RBC, WBC count with differential along with platelets count was further confirmed by manual oil immersion smear study method. Peripheral smears study was done with field A and B stain and leishman stain. Conclusion: Thrombocytopenia is one of the common complications of acute illness of the P. vivax malaria. After the Thrombocytopenia, raised platelets distribution width is a as prognostic tool and recovery survival index after acute illness p.vivex malaria.
\end{abstract}

Keyword-platelets distribution width, Thrombocytopenia.

\section{MATERIAL \& METHODS}

Study area and design- The present study was conducted at the Department of medicine and pathology curewell hospital Pvt Ltd Indore mp. The study was designed as a observational hospital based study.

Ethical Consideration- Blood was collected in a sterile EDTA containing tube and processed following our established hospital based laboratory protocol then generate the report of each patient. Take informed consent was obtained from all study participant for use of your blood sample for medical research after doing physician request investigating and generate the report. Start proper management as a guide line.
Patient's Selection Criteria- The study target those patients who's present with complain of fever with chills rigger. Blood sample pathology report shows plasmodium vivex malaria positive. We include both OPD and IPD patients with all age groups, male and female both gender for study. Sample size is 100 patients.

\section{COMPLETE BLOOD COUNT (CBC) AND PERIPHERAL SMEAR.}

\section{Materials}

Purple vacutainer tube or capillary collector (EDTA) ethylenediaminetetraacetate, Slides and blue capillary tube, Needle or lancet, Vacutainer holder, Alcohol swab, Cotton balls, Absorbent 
materials, Slide case and heamatological cell counter.

\section{Procedure}

1. Specimen is collected into EDTA (purple) vacutainer. ( 5 or $7 \mathrm{ml}$ volume)

$>$ Step 1. A small drop of venous blood is placed on a glass microscope slide, using a glass capillary pipette.

$>$ Step 2. A spreader slide is positioned at $45^{\circ}$ angle and slowly drawn toward the drop of blood.

$>$ Step 3. The spreader slide is brought in contact with the drop of blood and is being drawn away.

$>$ Step 4. The spreader slide is further pulled out, leaving a thin layer of blood behind.

$>$ Step 5. The blood smear is nearly complete.

$>$ Step 6. End result will be a glass slide with a well-formed blood film. After drying for about 10 minutes, the slide is fixed in methanol \& stained with field A and B stain.

Then the run the sample in hematological cell counter and generate PDW data.

Platelet count in the blood can be rapidly measured using an automated haematologic analyser. Platelet indices are biomarkers of platelet activation. They allow extensive clinical investigations focusing on the diagnostic and prognostic values in a variety of settings without bringing extra costs. Among these platelet indices, plateletcrit (PCT), mean platelet volume (MPV), and platelet distribution width (PDW) are a group of platelet parameters determined together in automatic CBC profiles; they are related to platelets' morphology and proliferation kinetics.

PDW is an indicator of volume variability in platelets size and is increased in the presence of platelet anisocytosis ${ }^{(17)}$. PDW is a distribution curve of platelets measured at the level of $20 \%$ relative height in a platelet-size distribution curve, with a total curve height of $100 \%{ }^{(18)}$. PDW directly measures variability in platelet size, changes with platelet activation, and reflects the heterogeneity in platelet morphology ${ }^{(13,20)}$. Under physiological conditions, there is a direct relationship between MPV and PDW; both usually change in the same direction (20). Meanwhile, there are conflicting reports in the literature about the relationship between platelet volume and numbers, which suggests that they are affected by different mechanisms ${ }^{(5,21-25)}$.

\section{Hematological Examination}

Hematological Examination including $\mathrm{HB} \%$, PCV, Red cell indices, platelet count and total white cell count with differential count should be done on peripheral smears stained with field A and $\mathrm{B}$ stains.

\section{OBERVATION \& DISCUSSION}

\begin{tabular}{|l|c|c|c|c|}
\hline \multirow{2}{*}{ Plasmodium Vivex } & \multirow{2}{*}{ VALUE } & \multirow{2}{*}{ Prognosis } & \multicolumn{2}{|c|}{ Total Cases (n=100) } \\
\cline { 4 - 5 } & & & No. & $\%$ \\
\hline PDW high & $17-20 \%$ & Poor prognosis & 63 & $63.00 \%$ \\
\hline PDW normal & Between 15- 16\% & Good prognosis & 36 & $36.00 \%$ \\
\hline PDW low & $<14 \%$ & Not significant & 01 & $01 \%$ \\
\hline
\end{tabular}

\begin{tabular}{|l|c|c|c|}
\hline \multirow{2}{*}{ Plasmodium Vivex } & \multirow{2}{*}{ Type of severity } & \multicolumn{2}{|c|}{ Total Cases $(\mathrm{n}=100)$} \\
\cline { 3 - 4 } & & No. & $\%$ \\
\hline PDW high & acute illness & 63 & $63 \%$ \\
\hline PDW normal or low & Non acute illness & 37 & $37 \%$ \\
\hline
\end{tabular}

This study comprised 100 individuals (67 male and 33 female). Blood samples were collected by venipuncture in tubes containing EDTA anticoagulant (ethylene diamine The platelet indices were analyzed in whole blood using a blood cell counter The factorial ANOVA model 
with Tukey's test was used for statistical analysis and an alpha error of 5\% (p-value < 0.05) was considered acceptable. The values for PDW were 15.4 TO $16.6 \%$ which are similar to the mean values quoted in the literature. ${ }^{(4)}$ In relation to gender, significant differences were observed only for the PCT levels. In regards to age, there were significant differences in the values for the three platelet indices comparing the under 10-year-old age group to the other age groups except for the all age group.

Data analysis in following hematological parameters with the difference under the Extended Mantel-Haenszel test for trend of chi -Squares test. Chi-sq. test X2 Value $=0.873[\mathrm{DF}=1] 2$ sided $\mathrm{P}=0.350$ For trend in a given direction: $\mathrm{P}$ $=0.175$

\section{CONCLUSION}

P.vivax monoinfection presented with thrombocytopenia and raised PDW suggesting that acute illness ${ }^{1,2}$. vivax malaria has now clearly emerged as a potentially lethal condition $\frac{11}{2 l}$, despite of having previously been (platelet count $<20 \times 10^{3} / \mathrm{mm}^{3}$ ) is a common manifestation in patients with vivax mono-infection confirmed by PCR ${ }^{[5], ~[6] . ~ t h r o m b o c y t o p e n i a ~ i n ~ m a l a r i a ~ s e e m s ~ t o ~}$ be a multifactorial phenomenon and probably involves an increase in platelets destruction and consumption ${ }^{\text {[7].[8]-[10] }}$.

$P$. vivax revealed a high frequency of thrombocytopaenia and raised PDW. The high frequency of warning signs of severe malaria cases can be explained by the fact that this study was conducted in a reference hospital for malaria diagnosis and treatment. to that reported ${ }^{[11]}$ [12] regarding patients infected with $P$. vivax in the Amazon region. Increased PDW in malaria has been observed in other studies maskar as acute illness. ${ }^{[13,14] \text {. }}$

It is well known that non-immune individuals are more susceptible to developing severe malaria. Furthermore, the delay of onset of malaria treatment is directly associated with severe disease outcomes ${ }^{[15]}$. Raised PDW predominated in the patients with any indicator of severe malaria caused by $P$. vivax, such as primary infection, longer symptom duration, and the presence of clinical signs and laboratory indicators of severe malaria. Larger platelets are metabolically and enzymatically more active and have a more important role in the inflammatory process ${ }^{[16]}$. Elevated PDW has also been described in patients with severe sepsis and is explained by the quick splenic and medullary release of large volumes of platelets in response to the increased demand for these cells ${ }^{[17]}$. In fact, studies in humans and rats showed that large platelets are functionally more active and have a lower threshold for aggregation and the release of their activity [ ${ }^{[, 16]}$. It is well known that PDW is linearly correlated with MPV in normal individuals. So raised PDW use as a prognostic tool for p.vivex of acute illness.

\section{REFERENCES}

1. J. Lou, Y. R. A. Donati, P. Juillard et al., "Platelets play an important role in TNFinduced microvascular endothelial cell pathology," The American Journal of Pathology, vol. 151, no. 5, pp. 1397-1405, 1997.

2. S. C. Wassmer, C. Lépolard, B. Traoré, B. Pouvelle, J. Gysin, and G. E. Grau, "Platelets reorient Plasmodium falciparum-infected erythrocyte cytoadhesion to activated endothelial cells," Journal of Infectious Diseases, vol. 189, no. 2, pp. 180-189, 2004.

3. S. C. Wassmer, J. B. De Souza, C. Frère, F. J. Candal, I. Juhan-Vague, and G. E. Grau, "TGF- $\beta 1$ released from activated platelets can induce TNF-stimulated human brain endothelium apoptosis: a new mechanism for microvascular lesion during cerebral malaria," Journal of Immunology, vol. 176, no. 2, pp. 11801184, 2006.

4. B. O. Carvalho, S. C. P. Lopes, P. A. Nogueira et al., "On the cytoadhesion of Plasmodium vivax-infected erythrocytes," Journal of Infectious Diseases, vol. 202, no. 4, pp. 638-647, 2010. 
5. A. J. Rodríguez-Morales, E. Sánchez, M. Vargas, et al., "Anemia and thrombocytopenia in children withPlasmodium vivax malaria," Journal of Tropical Pediatrics, vol. 52, pp. 49-51, 2005.

6. P. J. Beale, J. D. Cormack, and T. B. Oldrey, "Thrombocytopenia in malaria with immunoglobulin (IgM) changes, " British Medical Journal, vol. 1, no. 796, pp. 345-349, 1972.

7. WHO, "Severe falciparum malaria," Transactions of the Royal Society of Tropical Medicine and Hygiene, vol. 94, Supplement 1, pp. S1-S90, 2000.

8. M. V. G. Lacerda, Clinical manifestations and pathogenesis of malarial thrombocytopenia [Ph.D. thesis], Tropical Medicine Department, University of Brasília, 2007.

9. S. B. R. Silva, Evaluation of frequency and factors associated to thrombocytopenia caused by Plasmodium vivax [Master dissertation], Federal University of Mato Grosso, 2009.

10. P. Grynberg, C. J. Fernandes Fontes, and É. Martins Braga, "Association between particular polymorphic residues on apical membrane antigen 1 (AMA-1) and platelet levels in patients with vivax malaria," Clinical Microbiology and Infection, vol. 13, no. 11, pp. 1089-1094, 2007.

11. Franklin BS, Vitorino BLF, Coelho HC, Menezes-Neto A, Santos MLS, Campos FMF, Brito CF, Fontes CJ, Lacerda MV, Carvalho LH: Plasma circulating nucleic acids levels increase according to the morbidity of Plasmodium vivax malaria. PLoSOne 2011, 6:e19842.

12. Coelho HCC, Lopes SCP, Pimentel JPD, Nogueira PA, Costa FTM, Siqueira AM, Melo GC, Monteiro WM, Malheiro A, Lacerda MVG: Thrombocytopenia in Plasmodium vivaxmalaria is related to platelets phagocytosis.PLoS One 2013, 8:e63410.

13. Maina RN, Walsh D, Gaddy C, Hongo G, Waitumbi J, Otieno L, Jones D, Ogutu
BR: Impact of Plasmodium falciparum infection on haematological parameters in children living in western Kenya.Malar J 2010, 9(Suppl 3)

14. Ladhani S, Lowe B, Cole AO, Kowuondo $\mathrm{K}$, Newton CRJC: Changes in white blood cells and platelets in children with falciparum malaria: relationship to disease outcome. Br J Haematol 2002, 119:839847.

15. WHO: Guidelines for the treatment of malaria. 2nd edition. Geneva: World Health Organization; 2010.

16. Thon JN, Italiano JE: Does size matter in platelet production 2012, 120:1552-1561

17. Becchi C, Al Malyan M, Fabbri LP, Marsili M, Boddi V, Boncinelli S: Mean platelet volume trend in sepsis: is it a useful parameter Minerva Anestesiol 2006, 72:749-756. 